\title{
Quadruple C-H Bond Activations of Methane by Dinuclear Rhodium Carbide Cation $\left[\mathrm{Rh}_{2} \mathrm{C}_{3}\right]^{+}$
}

\author{
Hechen Wu, Xiao-Nan Wu,* Xiaoyang Jin, Yangyu Zhou, Wei Li, Chonglei Ji, and Mingfei Zhou* \\ Cite This: JACS Au 2021, 1, 1631-1638 \\ Read Online
}

ABSTRACT: The structure of the $\left[\mathrm{Rh}_{2} \mathrm{C}_{3}\right]^{+}$ion and its reaction with $\mathrm{CH}_{4}$ in the gas phase have been studied by infrared photodissociation spectroscopy and mass spectrometry in conjunction with quantum chemical calculations. The $\left[\mathrm{Rh}_{2} \mathrm{C}_{3}\right]^{+}$ion is characterized to have an unsymmetrical linear [ $\mathrm{Rh}-\mathrm{C}-\mathrm{C}-\mathrm{C}-$ $\mathrm{Rh}]^{+}$structure existing in two nearly isoenergetic spin states. The $\left[\mathrm{Rh}_{2} \mathrm{C}_{3}\right]^{+}$ion reacts with $\mathrm{CH}_{4}$ at room temperature to form $\left[\mathrm{Rh}_{2} \mathrm{C}\right]^{+}+\mathrm{C}_{3} \mathrm{H}_{4}$ and $\left[\mathrm{Rh}_{2} \mathrm{C}_{2} \mathrm{H}_{2}\right]^{+}+\mathrm{C}_{2} \mathrm{H}_{2}$ as the major products. In addition to the $\left[\mathrm{Rh}_{2} \mathrm{C}\right]^{+}$ion, the $\left[\mathrm{Rh}_{2}{ }^{13} \mathrm{C}\right]^{+}$ion is formed at about one-half of the $\left[\mathrm{Rh}_{2} \mathrm{C}\right]^{+}$intensity when the isotopic-labeled ${ }^{13} \mathrm{CH}_{4}$ sample is used. The production of $\left[\mathrm{Rh}_{2}{ }^{13} \mathrm{C}\right]^{+}$indicates that

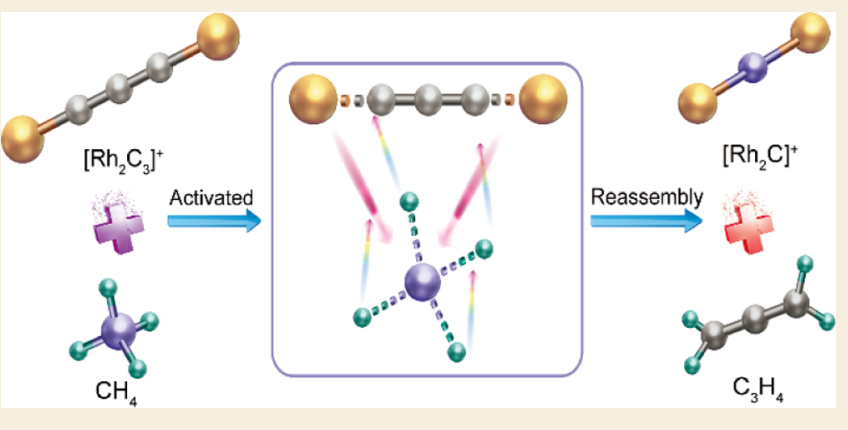
the linear $\mathrm{C}_{3}$ moiety of $\left[\mathrm{Rh}_{2} \mathrm{C}_{3}\right]^{+}$can be replaced by the bare carbon atom of methane with all four $\mathrm{C}-\mathrm{H}$ bonds being activated. The calculations suggest that the overall reactions are thermodynamically exothermic, and that the two $\mathrm{Rh}$ centers are the reactive sites for $\mathrm{C}-\mathrm{H}$ bond activation and hydrogen atom transfer reactions.

KEYWORDS: methane activation, rhodium carbide, mass spectrometry, infrared photodissociation spectroscopy, quantum chemical calculation.

\section{INTRODUCTION}

Methane is a naturally abundant molecule and is one of the most potent greenhouse gases contributing to global warming. It is extremely stable with very high $\mathrm{C}-\mathrm{H}$ bond strengths (439, 463,443 , and $339 \mathrm{~kJ} / \mathrm{mol}$ for the four $\mathrm{C}-\mathrm{H}$ bonds), negligible electron affinity, and low polarizability. ${ }^{1}$ Consequently, the activation and conversion of methane into value-added chemicals is very important but is quite challenging. ${ }^{2-6}$ For some chemical transformation processes, such as the conversion of methane to syngas, it needs the activation of all the four $\mathrm{C}-\mathrm{H}$ bonds of methane. These reaction processes always demand high temperature and pressure. ${ }^{7}$ Systems that can activate methane at mild conditions are in high demand. Many examples of methane activation at transition-metal centers have been reported. ${ }^{8-13}$ To develop practical methane conversion processes, much remains to be learned about the processes and factors controlling the activity and selectivity of catalytic reactions. Gas-phase reactions of transition-metal atoms, ions, and clusters with methane serve as simple models in understanding the intrinsic mechanism of the catalytic methane conversion processes. ${ }^{14-24}$

Transition-metal carbides and carbide-based surfaces were found to be able to activate methane at mild conditions. ${ }^{25-29}$ In view of this, the reactivity of transition metal carbide ions with methane has been intensively investigated in the gas phase by mass spectrometry and quantum chemical calculations. ${ }^{30-41}$
Mechanistic aspects of the $\mathrm{C}-\mathrm{H}$ bond activation of methane by diatomic transition metal carbide cations were elucidated by quantum-chemical calculations and verified experimentally using mass spectrometry. ${ }^{30-35}$ The activation of methane by metal-carbide cations was found and proposed to proceed via different mechanisms including hydrogen atom transfer (HAT) and proton-coupled electron transfer (PCET), as well as hydride transfer (HT). ${ }^{33}$ Simultaneous activation of two $\mathrm{C}-\mathrm{H}$ bonds of methane was identified in the reaction of the copper carbide cation. ${ }^{32,33}$ The bond dissociation energies, spin states, number of d-electrons, and charge distributions of the metal carbide cations are factors that jointly affect both the reactivity and the mechanism of $\mathrm{C}-\mathrm{H}$ bond activation. ${ }^{33}$ Transition-metal carbide anions are usually not very reactive with methane. However, it was found that the $\mathrm{FeC}_{6}{ }^{-}$anion can activate $\mathrm{CH}_{4}$ via a dissociative adsorption manner. ${ }^{36}$ The large dipole moment of $\mathrm{FeC}_{6}{ }^{-}$can induce a polarization of $\mathrm{CH}_{4}$, which facilitates cleavage of the $\mathrm{C}-\mathrm{H}$ bond. The $\mathrm{FeC}_{3}{ }^{-}$anion reacts with methane under high-temperature conditions to

Received: June 12, 2021

Published: September 4, 2021 
form the $\mathrm{C}-\mathrm{C}$ coupling product acetylene. ${ }^{37}$ The reactions of other metal carbide cluster ions with methane have also been reported. ${ }^{38-41}$ Most clusters show high reactivity toward $\mathrm{CH}_{4}$ dehydrogenation at thermal conditions. The cooperation of the metal centers in the dinuclear carbide cluster reaction has been proposed. ${ }^{39}$ The $\mathrm{C}-\mathrm{H}$ bond activation takes place predominantly around one Ta center in the initial stage of the reaction, and the second $\mathrm{Ta}$ center accepts the delivered $\mathrm{H}$ atom from the $\mathrm{C}-\mathrm{H}$ bond cleavage. ${ }^{39}$

In this paper, we report a combined experimental and theoretical study on the reaction of a dinuclear rhodium carbide cation $\left[\mathrm{Rh}_{2} \mathrm{C}_{3}\right]^{+}$with methane in the gas phase. We will show that the reactions involving the activation of all four $\mathrm{C}-\mathrm{H}$ bonds of the methane and carbon atom exchange processes proceed at thermal conditions.

\section{EXPERIMENTAL AND COMPUTATIONAL METHODS}

The infrared photodissociation spectrum of the $\left[\mathrm{Rh}_{2} \mathrm{C}_{3} \cdot \mathrm{Ar}\right]^{+}$ions was measured using a collinear tandem time-of-flight mass spectrometer as described in detail previously. ${ }^{42}$ The rhodium carbide cations were generated in the gas phase using a pulsed laser vaporizationsupersonic expansion ion source. The fundamental of a Nd:YAG laser with $10-20 \mathrm{~mJ} /$ pulse was employed to ablate a rhodium + graphite (1:4) target. The cation complexes were produced during the laser ablation process in supersonic expansions of helium or Ar gas mixtures at about 1.0 MPa backing pressure. After free expansion and cooling, the ions were extracted and analyzed using a time of-flight mass spectrometer. The $\left[\mathrm{Rh}_{2} \mathrm{C}_{3} \cdot \mathrm{Ar}\right]^{+}$ions were mass-selected, decelerated, and subjected to IR photodissociation by a tunable IR laser. The fragment and undissociated parent ions were reaccelerated and mass analyzed by a second collinear time-of-flight mass spectrometer. Infrared photodissociation spectrum was obtained by monitoring the fragment ion yield (the intensity of fragment ions divided by the sum of intensities of the fragment ions and the undissociated parent ions) as a function of the dissociation IR laser wavelength. The tunable infrared source is generated by an KTP/ $\mathrm{KTA} / \mathrm{AgGaSe} 2$ optical parametric oscillator/amplifier system (OPO/ OPA, Laser Vision) pumped by a Continuum Surelite Nd:YAG laser, which is tunable in the range of $800-5000 \mathrm{~cm}^{-1}$ with an approximate line width of $2 \mathrm{~cm}^{-1}$. Typical spectra were recorded by scanning the dissociation laser in steps of $2 \mathrm{~cm}^{-1}$ and averaging over 250 laser shots at each wavelength. The laser pulse energy ranges from 0.2 to $1.5 \mathrm{~mJ} /$ pulse.

The reaction of $\left[\mathrm{Rh}_{2} \mathrm{C}_{3}\right]^{+}$ions with methane was studied using an ion trap mass spectrometer. ${ }^{43}$ The ions generated by a pulsed laser vaporization-supersonic expansion ion source were mass-selected by a quadrupole and then were sent into a quadrupole linear ion trap, where the ions were accumulated and thermalized to room temperature by helium gas for $20 \mathrm{~ms}$ with an estimated number of collisions of $2800 .^{44}$ The $\left[\mathrm{Rh}_{2} \mathrm{C}_{3}\right]^{+}$ions reacted with methane introduced by a pulsed valve. After a $10 \mathrm{~ms}$ reaction, the trapped ions were successively ejected through the slit of the ion trap according to the mass-to-charge ratio by scanning the radio frequency (rf) from 150 to $500 \mathrm{~V}$ over $80 \mathrm{~ms}$. The ejected ions were detected by electron multipliers with dynodes (DeTech 397).

Theoretical calculations were performed using the Gaussian 09 package at the dispersion corrected B3LYP-D3/def2TZVP level of theory. ${ }^{45-49}$ The Molclus program was used to search for the possible stable structures of the reactants and products. ${ }^{50}$ The low-lying stable isomers were then reoptimized at the B3LYP-D3/def2TZVP level to confirm the relative energy sequence. The stability of the wave functions for each optimized structure is checked. Calculations at this level of theory can provide reliable predictions on the $\mathrm{C}-\mathrm{H}$ bond dissociation energies of methane, propyne, and allene with deviations less than $20 \mathrm{~kJ} / \mathrm{mol}$ with respect to the experimental values (Table S1)..$^{51,52}$ The prediction of the $\mathrm{Rh}^{+}-\mathrm{H}$ bonds of $\mathrm{RhH}^{+}$and $\mathrm{RhCH}_{3}{ }^{+}$is slightly less accurate with deviations of 26 and $43 \mathrm{~kJ} / \mathrm{mol}$ from the experimental values. ${ }^{53,54}$ The excitation energies ${ }^{1} \mathrm{D} \rightarrow{ }^{3} \mathrm{~F}$ and ${ }^{5} \mathrm{~F} \rightarrow$ ${ }^{3} \mathrm{~F}$ of $\mathrm{Rh}^{+}$are predicted to be deviated by 57 and $13 \mathrm{~kJ} / \mathrm{mol}$ from the experimental values (Table S2). ${ }^{55}$ The transition state optimizations were performed with the synchronous transit-guided quasi-Newton (STQN) method and were verified through intrinsic reaction coordinate (IRC) calculations. ${ }^{56-58}$ Vibrational frequency calculations were performed to identify the nature of reaction intermediates, transition states (TSs), and products. The harmonic vibrational frequencies are scaled by a factor of 0.964 according to the Computational Chemistry Comparison and Benchmark Database. ${ }^{59}$

\section{RESULTS AND DISCUSSION}

To determine the geometric and electronic structures of the $\left[\mathrm{Rh}_{2} \mathrm{C}_{3}\right]^{+}$cation, infrared photodissociation spectroscopy is employed to obtain the vibrational spectrum of $\left[\mathrm{Rh}_{2} \mathrm{C}_{3}\right]^{+}$. The dissociation energies of the $\left[\mathrm{Rh}_{2} \mathrm{C}_{3}\right]^{+}$cation are calculated to be $504,690,578$, and $393 \mathrm{~kJ} / \mathrm{mol}$, respectively, with respect to the $[\mathrm{RhCCC}]^{+}+\mathrm{Rh},[\mathrm{RhCC}]^{+}+\mathrm{RhC},[\mathrm{RhC}]^{+}+\mathrm{RhCC}$, and $[\mathrm{Rh}]^{+}+\mathrm{RhCCC}$ dissociation channels at the B3LYP-D3/ def2TZVP level. Because the dissociation energies of the $\left[\mathrm{Rh}_{2} \mathrm{C}_{3}\right]^{+}$cation are predicted to be significantly greater than the infrared photon energies in the $\mathrm{C}-\mathrm{C}$ and $\mathrm{Rh}-\mathrm{C}$ stretching frequency region, the method of rare-gas atom predissociation is employed. ${ }^{60-63}$ The Ar-tagged complex $\left[\mathrm{Rh}_{2} \mathrm{C}_{3} \cdot \mathrm{Ar}\right]^{+}$is generated and mass-selected for infrared photodissociation. When the infrared laser is in resonance with one of the vibrational fundamentals of the $\left[\mathrm{Rh}_{2} \mathrm{C}_{3} \cdot \mathrm{Ar}\right]^{+}$complex, it photodissociates by eliminating an argon atom. The resulting infrared spectrum is shown in Figure 1a. Two close-lying bands centered at 1984 and $2011 \mathrm{~cm}^{-1}$ together with a weak broad band centered at $1384 \mathrm{~cm}^{-1}$ are observed. The two bands around $2000 \mathrm{~cm}^{-1}$ are very close to the antisymmetric stretching mode of linear $\mathrm{C}_{3}$ molecule at $2040 \mathrm{~cm}^{-1}, 64,65$ suggesting that the $\left[\mathrm{Rh}_{2} \mathrm{C}_{3}\right]^{+}$cation involves a $\mathrm{C}_{3}$ subunit. The $1384 \mathrm{~cm}^{-1}$ band can be attributed to the symmetric stretching vibration of the $C_{3}$ unit. The observation of the symmetric stretching mode suggests that the $\mathrm{C}_{3}$ subunit is either bent or asymmetric.

As shown in Figure 2, the most stable structure of the $\left[\mathrm{Rh}_{2} \mathrm{C}_{3}\right]^{+}$cation is predicted to have a linear asymmetric structure $[\mathrm{Rh}-\mathrm{C}-\mathrm{C}-\mathrm{C}-\mathrm{Rh}]^{+}$with two different $\mathrm{Rh}-\mathrm{C}$ bonds of 1.90 and $1.72 \AA$, respectively. The two $\mathrm{C}-\mathrm{C}$ bonds are also not the same with a shorter bond distance of $1.24 \AA$ and a longer bond distance of $1.32 \AA$. The doublet ${ }^{2} \Delta$ state and the quartet ${ }^{4} \Delta$ state are nearly isoenergetic and have essentially the same geometric parameters and valence electron configuration of $\pi^{4} \delta^{4} \delta^{3} \sigma^{1} \sigma^{1}$. The unpaired electrons occupy the rhodiumbased molecular orbitals as shown in Figure 3 . The quartet state, in which the unpaired electrons at the terminal rhodium atoms are ferromagnetically coupled is predicted to be $1 \mathrm{~kJ} /$ mol higher in energy than the doublet state with antiferromagnetic coupling of the unpaired electrons at the terminal rhodium atoms at the B3LYP level (Table 1). The quartet state is predicted to be $2 \mathrm{~kJ} / \mathrm{mol}$ more stable than the doublet state at the CCSD $(\mathrm{T}) / / \mathrm{B} 3 \mathrm{LYP}-\mathrm{D} 3 /$ def2TZVP level. ${ }^{66}$ The other nonlinear structures are predicted to lie more than $98 \mathrm{~kJ} / \mathrm{mol}$ higher in energy than the most stable linear structure as shown in Figure S1. The argon-tagged complexes of the linear $\left[\mathrm{Rh}_{2} \mathrm{C}_{3}\right]^{+}$ions are also calculated at the B3LYPD3/def2TZVP level. The results show that the argon atom prefers to coordinate to the terminal rhodium atom with two unpaired electrons (with longer $\mathrm{Rh}-\mathrm{C}$ bond) for both the quartet and doublet spin states (see Figure S1 and Table S3). The calculations also show that the energetic ordering of the 


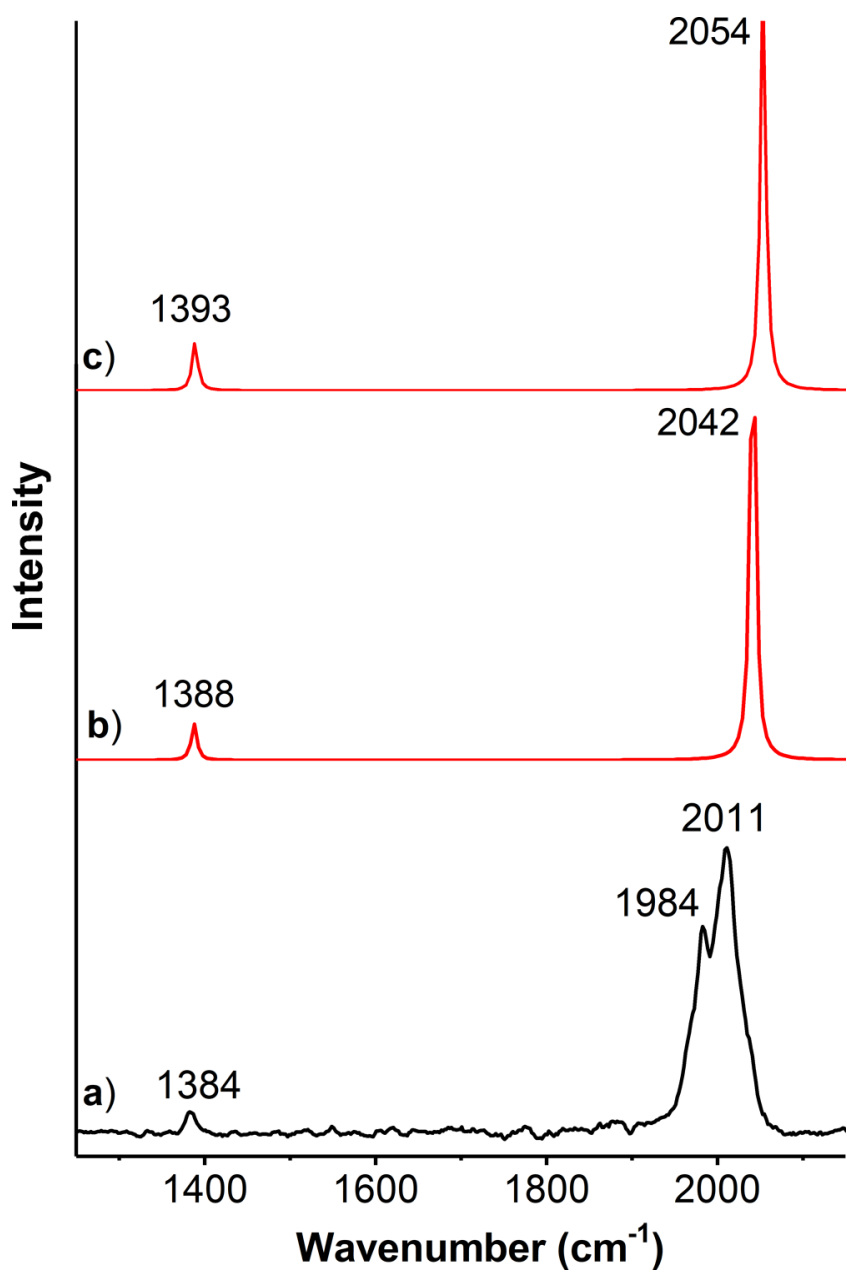

Figure 1. Experimental and simulated infrared spectra of $\left[\mathrm{Rh}_{2} \mathrm{C}_{3} \cdot \mathrm{Ar}\right]^{+}$. (a) Experimental infrared photodissociation spectrum, (b) simulated spectrum of the doublet state, and (c) simulated spectrum of the quartet state. The simulated spectra are obtained by applying Lorentzian functions with the theoretical harmonic vibrational frequencies scaled by a factor of 0.964 and a $5 \mathrm{~cm}^{-1}$ full width at half-maximum (fwhm).

doublet and quartet spin states is not affected by weak argon coordination. The $\mathrm{Rh}-\mathrm{Ar}$ distances are quite large (2.64 and $2.67 \AA)$ and the $\left[\mathrm{Rh}_{2} \mathrm{C}_{3}\right]^{+}$moiety in $\left[\mathrm{Rh}_{2} \mathrm{C}_{3} \cdot \mathrm{Ar}\right]^{+}$has essentially the same structure as the free cation as shown in Figure 2. The antisymmetric and symmetric $\mathrm{C}_{3}$ stretching modes of the doublet state $\left[\mathrm{Rh}_{2} \mathrm{C}_{3} \cdot \mathrm{Ar}\right]^{+}$ion are calculated at 2042 and $1388 \mathrm{~cm}^{-1}$, whereas these two modes of the quartet spin state are predicted at 2054 and $1393 \mathrm{~cm}^{-1}$ (Table 1). On the basis of the comparison between the simulated and experimental infrared spectra (Figure 1), the experimentally observed $\left[\mathrm{Rh}_{2} \mathrm{C}_{3}\right]^{+}$ion can be attributed to have the unsymmetrical linear $[\mathrm{Rh}-\mathrm{C}-\mathrm{C}-\mathrm{C}-\mathrm{Rh}]^{+}$structure coexisting in the two nearly isoenergetic doublet and quartet spin states. The observed 1984 and $2011 \mathrm{~cm}^{-1}$ bands separated by 27 $\mathrm{cm}^{-1}$ are assigned to the antisymmetric $\mathrm{C}_{3}$ stretching modes of the ions in the doublet and quartet spin states, respectively. The symmetric stretching modes of the two spin states are predicted to be separated by only $5 \mathrm{~cm}^{-1}$, and thus cannot be resolved experimentally. The coexistence of two spin states has been reported for other ions previously. ${ }^{34,39}$

The mass spectra from the reactions of mass-selected $\left[\mathrm{Rh}_{2} \mathrm{C}_{3}\right]^{+}$ions $(m / z=242)$ with $\mathrm{He}, \mathrm{CH}_{4},{ }^{13} \mathrm{CH}_{4}$, and $\mathrm{CD}_{4}$ in
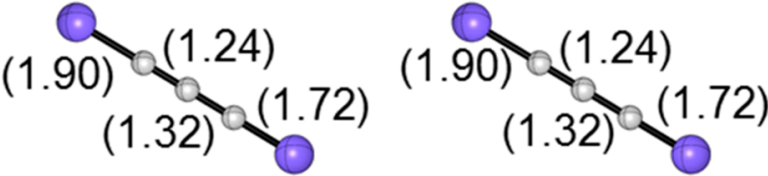
$\left[\mathrm{Rh}_{2} \mathrm{C}_{3}\right]^{+},{ }^{2} \Delta, \mathrm{C}_{\infty \mathrm{V}}$
$\Delta \mathrm{E}=0$

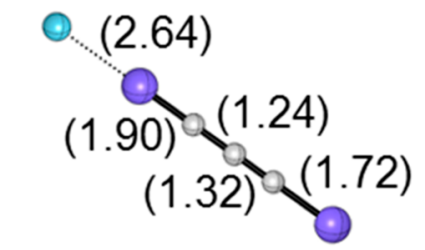

$\left[\mathrm{Rh}_{2} \mathrm{C}_{3} \cdot \mathrm{Ar}\right]^{+},{ }^{2} \Delta, \mathrm{C}_{\infty \mathrm{V}}$ $\Delta \mathrm{E}=0$
$\left[\mathrm{Rh}_{2} \mathrm{C}_{3}\right]^{+},{ }^{4} \Delta, \mathrm{C}_{\infty \mathrm{V}}$
$\Delta \mathrm{E}=1$

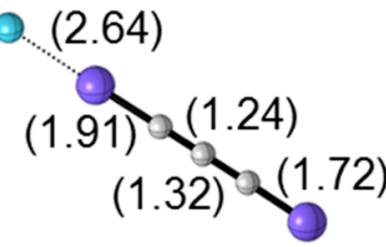

Figure 2. Optimized structures (bond lengths in $\AA$ ) of the linear $\left[\mathrm{Rh}_{2} \mathrm{C}_{3}\right]^{+}$ion and its Ar-tagged $\left[\mathrm{Rh}_{2} \mathrm{C}_{3} \cdot \mathrm{Ar}\right]^{+}$complex at the B3LYPD3/def2TZVP level of theory. The relative energies are given in $\mathrm{kJ} /$ mol. Purple, Rh; gray, C; light blue, Ar.

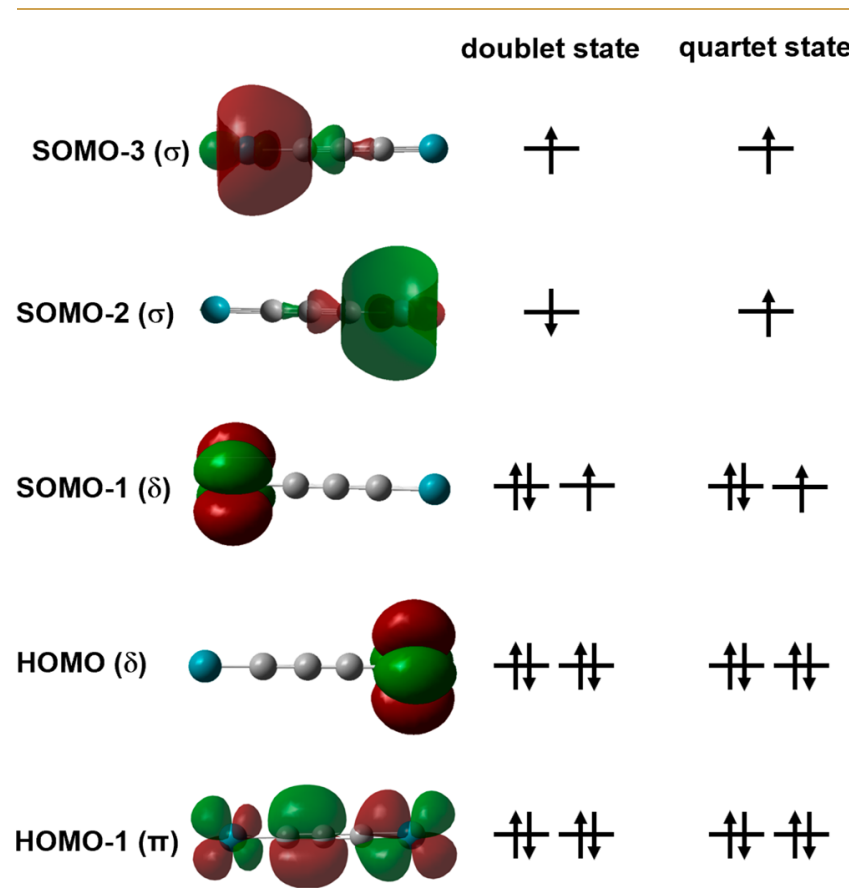

Figure 3. Frontier molecular orbitals of $\left[\mathrm{Rh}_{2} \mathrm{C}_{3}\right]^{+}$in the doublet and quartet spin states. (SOMO $-1, \mathrm{HOMO}$, and HOMO -1 are doubly degenerate, and only one orbital is shown).

the ion trap at room temperature are shown in Figure 4. No product ion is observed in the mass spectrum using pure $\mathrm{He}$ as reactant gas (Figure 4a), while two mass peaks at $m / z=218$ and 232 , which can be attributed to the product ions with chemical formulas of $\left[\mathrm{Rh}_{2} \mathrm{C}\right]^{+}$and $\left[\mathrm{Rh}_{2} \mathrm{C}_{2} \mathrm{H}_{2}\right]^{+}$, are observed to be the major reaction products (Figure $4 \mathrm{~b}$ ). A very weak mass peak at $m / z=256$ is also observed, which is assigned to the ion with chemical formula of $\left[\mathrm{Rh}_{2} \mathrm{C}_{4} \mathrm{H}_{2}\right]^{+}$(Figure $4 \mathrm{~b}$ ). The mass spectrum suggests that three reaction channels are observed for the $\left[\mathrm{Rh}_{2} \mathrm{C}_{3}\right]^{+}$and $\mathrm{CH}_{4}$ reactions. The first channel is the formation of the $\left[\mathrm{Rh}_{2} \mathrm{C}\right]^{+}$cation with the release 
Table 1. Experimental and Calculated Vibrational Frequencies of the $\left[\mathrm{Rh}_{2} \mathrm{C}_{3} \cdot \mathrm{Ar}\right]^{+}$and $\left[\mathrm{Rh}_{2} \mathrm{C}_{3}\right]^{+}$Ions and Calculated $\mathrm{Relative}$ Energy $(\Delta E$, in $\mathrm{kJ} / \mathrm{mol})$, Argon Binding Energy (BDE, in $\mathrm{kJ} / \mathrm{mol}$ ) and IR Intensities $(\mathrm{in} \mathrm{km} / \mathrm{mol})^{a}$

\begin{tabular}{|c|c|c|c|c|c|c|}
\hline & $\Delta E(\mathrm{~kJ} / \mathrm{mol})$ & $\operatorname{BDE}(\mathrm{kJ} / \mathrm{mol})$ & mode & obsd $\left(\mathrm{cm}^{-1}\right)$ & calcd $\left(\mathrm{cm}^{-1}\right)$ & IR intensities $\left(\mathrm{km} \mathrm{mol}^{-1}\right)$ \\
\hline \multirow[t]{2}{*}{${ }^{2}\left[\mathrm{Rh}_{2} \mathrm{C}_{3} \cdot \mathrm{Ar}\right]^{+}$} & 0 & 35 & a & 1984 & 2042 & 1688 \\
\hline & & & $\mathrm{s}$ & 1384 & 1388 & 135 \\
\hline \multirow[t]{2}{*}{${ }^{4}\left[\mathrm{Rh}_{2} \mathrm{C}_{3} \cdot \mathrm{Ar}\right]^{+}$} & +1 & 35 & a & 2011 & 2054 & 1793 \\
\hline & & & $\mathrm{s}$ & 1384 & 1393 & 140 \\
\hline \multirow[t]{2}{*}{${ }^{2}\left[\mathrm{Rh}_{2} \mathrm{C}_{3}\right]^{+}$} & 0 & & a & & 2043 & 1449 \\
\hline & & & $\mathrm{s}$ & & 1385 & 141 \\
\hline \multirow[t]{2}{*}{${ }^{4}\left[\mathrm{Rh}_{2} \mathrm{C}_{3}\right]^{+}$} & +1 & & a & & 2054 & 1544 \\
\hline & & & $\mathrm{s}$ & & 1390 & 149 \\
\hline
\end{tabular}

${ }^{a_{\text {The }}}$ symbols "a" and "s" denote anti-symmetric and symmetric stretching modes of the $\mathrm{C}_{3}$ subunit in the ions.

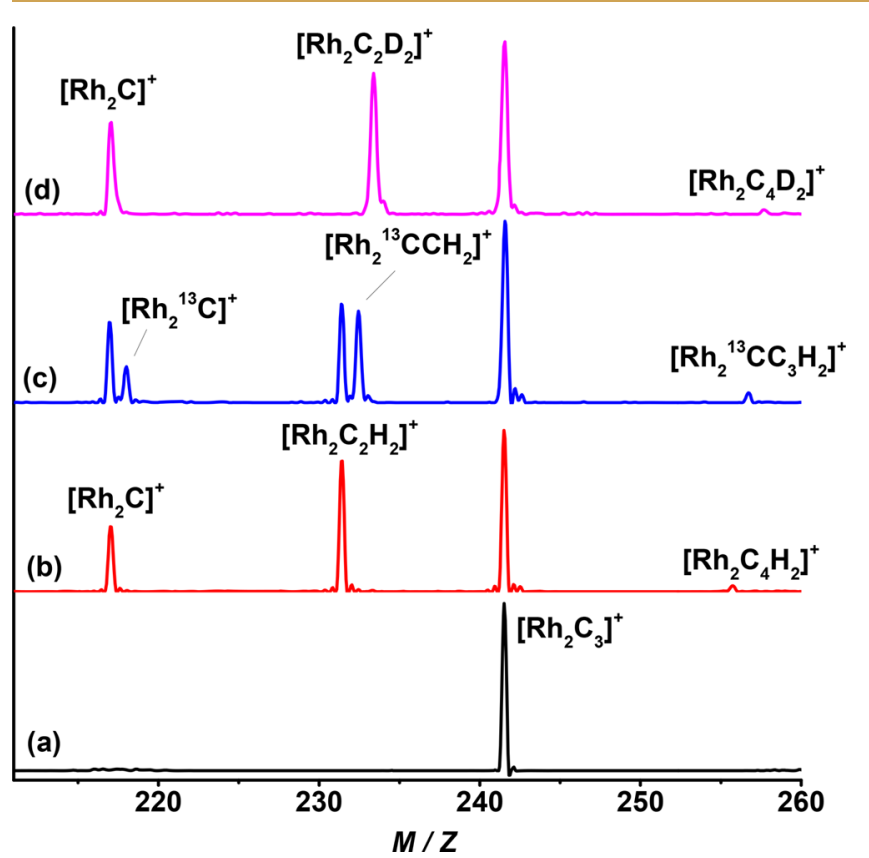

Figure 4. Mass spectra from the reactions of the $\left[\mathrm{Rh}_{2} \mathrm{C}_{3}\right]^{+}$ion with (a) $\mathrm{He},(\mathrm{b}) \mathrm{CH}_{4}$, (c) ${ }^{13} \mathrm{CH}_{4}$, and (d) $\mathrm{CD}_{4}$.

of a neutral $\mathrm{C}_{3} \mathrm{H}_{4}$ molecule (reaction 1). According to the thermochemical data, the heat of formation of propyne $\mathrm{CH}_{3} \mathrm{CCH}(185.71 \pm 0.24 \mathrm{~kJ} / \mathrm{mol})$ is only slightly lower than that of allene $\mathrm{CH}_{2} \mathrm{CCH}_{2}(189.93 \pm 0.25 \mathrm{~kJ} / \mathrm{mol}),{ }^{51}$ which suggests that both propyne and allene are formed in the reactions. The second channel is the generation of the $\left[\mathrm{Rh}_{2} \mathrm{C}_{2} \mathrm{H}_{2}\right]^{+}$ion with concomitant elimination of a neutral acetylene molecule $\mathrm{C}_{2} \mathrm{H}_{2}$ (reaction 2). The third channel is the generation of the $\left[\mathrm{Rh}_{2} \mathrm{C}_{4} \mathrm{H}_{2}\right]^{+}$ion with the release of a dihydrogen molecule as shown in reaction 3 :

$$
\begin{aligned}
& {\left[\mathrm{Rh}_{2} \mathrm{C}_{3}\right]^{+}+\mathrm{CH}_{4} \rightarrow\left[\mathrm{Rh}_{2} \mathrm{C}\right]^{+}+\mathrm{C}_{3} \mathrm{H}_{4}} \\
& {\left[\mathrm{Rh}_{2} \mathrm{C}_{3}\right]^{+}+\mathrm{CH}_{4} \rightarrow\left[\mathrm{Rh}_{2} \mathrm{C}_{2} \mathrm{H}_{2}\right]^{+}+\mathrm{C}_{2} \mathrm{H}_{2}} \\
& {\left[\mathrm{Rh}_{2} \mathrm{C}_{3}\right]^{+}+\mathrm{CH}_{4} \rightarrow\left[\mathrm{Rh}_{2} \mathrm{C}_{4} \mathrm{H}_{2}\right]^{+}+\mathrm{H}_{2}}
\end{aligned}
$$

The collision induced dissociation experiments (Figure S11) and the experiments using argon as the buffer gas (Figure S12) indicate that the contribution from collision-induced dissociation can clearly be ruled out. The reaction channel assignment is supported by the experiments with isotopic-labeled methane samples. Interesting results are observed when the ${ }^{13} \mathrm{CH}_{4}$ sample is employed (Figure $4 \mathrm{c}$ ). Both the $\left[\mathrm{Rh}_{2} \mathrm{C}_{2} \mathrm{H}_{2}\right]^{+}$and $\left[\mathrm{Rh}_{2}{ }^{13} \mathrm{CCH}_{2}\right]^{+}$product ions are observed to have approx- imately the same intensity, indicating that one or both carbon atoms of the eliminated $\mathrm{C}_{2} \mathrm{H}_{2}$ neutral molecule come from the $\left[\mathrm{Rh}_{2} \mathrm{C}_{3}\right]^{+}$ion. This suggests that there are $\mathrm{C} / \mathrm{C}$ exchange processes for the generation of $\left[\mathrm{Rh}_{2}{ }^{13} \mathrm{CCH}_{2}\right]^{+}$. Besides the $\left[\mathrm{Rh}_{2} \mathrm{C}\right]^{+}$ion, the $\left[\mathrm{Rh}_{2}{ }^{13} \mathrm{C}\right]^{+}$ion is also formed to have about one-half of the $\left[\mathrm{Rh}_{2} \mathrm{C}\right]^{+}$intensity. This is different with purely statistical expectations. The observation of $\left[\mathrm{Rh}_{2}{ }^{13} \mathrm{C}\right]^{+}$indicates that the carbon atom can originate from the $\mathrm{CH}_{4}$ reactant, implying that all the four $\mathrm{C}-\mathrm{H}$ bonds are activated and transferred to the $\mathrm{C}_{3}$ moiety of the $\left[\mathrm{Rh}_{2} \mathrm{C}_{3}\right]^{+}$ion during the reaction (see reaction 4 ). The $\left[\mathrm{Rh}_{2} \mathrm{C}\right]^{+},\left[\mathrm{Rh}_{2} \mathrm{C}_{2} \mathrm{D}_{2}\right]^{+}$and $\left[\mathrm{Rh}_{2} \mathrm{C}_{4} \mathrm{D}_{2}\right]^{+}$product ions are observed when the $\mathrm{CD}_{4}$ sample is employed (Figure 4d), which also support the proposed reactions $1-3$.

$$
\left[\mathrm{Rh}_{2} \mathrm{C}_{3}\right]^{+}+{ }^{13} \mathrm{CH}_{4} \rightarrow\left[\mathrm{Rh}_{2}{ }^{13} \mathrm{C}\right]^{+}+\mathrm{C}_{3} \mathrm{H}_{4}
$$

The variation in ion intensities of the reactant $\left(\left[\mathrm{Rh}_{2} \mathrm{C}_{3}\right]^{+}\right)$and products $\left(\left[\mathrm{Rh}_{2} \mathrm{C}\right]^{+},\left[\mathrm{Rh}_{2} \mathrm{C}_{2} \mathrm{H}_{2}\right]^{+}\right.$, and $\left.\left[\mathrm{Rh}_{2} \mathrm{C}_{4} \mathrm{H}_{2}\right]^{+}\right)$with respect to the $\mathrm{CH}_{4}$ pressure is given in Figure $\mathrm{S} 2$. The relative intensity of the reactant ion decreases and those of the product ions increase gradually as the pressure of reactant molecule $\mathrm{CH}_{4}$ increases. The number of $\mathrm{CH}_{4}$ is much larger than that of the $\left[\mathrm{Rh}_{2} \mathrm{C}_{3}\right]^{+}$ion in the ion trap, and the plots fit the pseudofirst-order kinetics. The rate constant $k\left(\left[\mathrm{Rh}_{2} \mathrm{C}_{3}\right]^{+}+\mathrm{CH}_{4}\right)$ is determined to be $2.5 \times 10^{-11} \mathrm{~cm}^{3} \mathrm{~s}^{-1}$ molecule ${ }^{-1}$. The collision rate is calculated to be $9.7 \times 10^{-10} \mathrm{~cm}^{3} \mathrm{~s}^{-1}$ using the Langevin-Gioumousis-Stevenson model, ${ }^{67,68}$ indicating that the reaction being observed occurs with an efficiency of only $2.6 \%$. The uncertainty on this rate constants are estimated to be accurate within a factor of 3 .

To gain insight into the reaction mechanism, the potential energy profiles are calculated. All of the three reactions 1-3 leading to the most stable structures of the products are exothermic by 27,21 , and $46 \mathrm{~kJ} / \mathrm{mol}$, respectively at the B3LYP level. The most favorable pathway for the $\left[\mathrm{Rh}_{2} \mathrm{C}_{3}\right]^{+}+$ $\mathrm{CH}_{4}$ reaction leading to the $\left[\mathrm{Rh}_{2} \mathrm{C}\right]^{+}+\mathrm{C}_{3} \mathrm{H}_{4}$ products on the doublet spin state is shown in Figure 5, and the other possible pathways are given in Figures S3-S5. The most stable structure of $\left[\mathrm{Rh}_{2} \mathrm{C}\right]^{+}$is linear with a doublet ground state $\left([\mathrm{Rh}-\mathrm{C}-\mathrm{Rh}]^{+}\right.$, Figure $\left.\mathrm{S} 6\right)$. Both the doublet state and quartet state $\left[\mathrm{Rh}_{2} \mathrm{C}_{3}\right]^{+}$ions can involve in the reaction with methane. All of the intermediates and transition states along the reaction pathways on the quartet state surface are about the same or higher in energy than those in the doublet state surface (Table S4). On the doublet state surface, the reaction proceeds with the initial formation of the adsorption complex $\left({ }^{2} 1\right)$, which is $39 \mathrm{~kJ} / \mathrm{mol}$ lower in energy than the doublet ground-state reactants. The complex has a $C_{s}$ symmetric structure with the $\mathrm{CH}_{4}$ molecule coordinated to the $\left[\mathrm{Rh}_{2} \mathrm{C}_{3}\right]^{+}$ion via two 


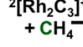

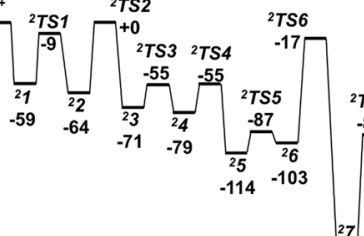

$\bullet \mathrm{Rh} \circ \mathrm{C} \bullet \mathrm{C}$ in $\mathrm{CH}_{4} \circ \mathrm{H}$

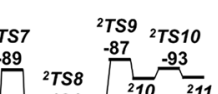
$\overbrace{28}^{-134}-113-109$
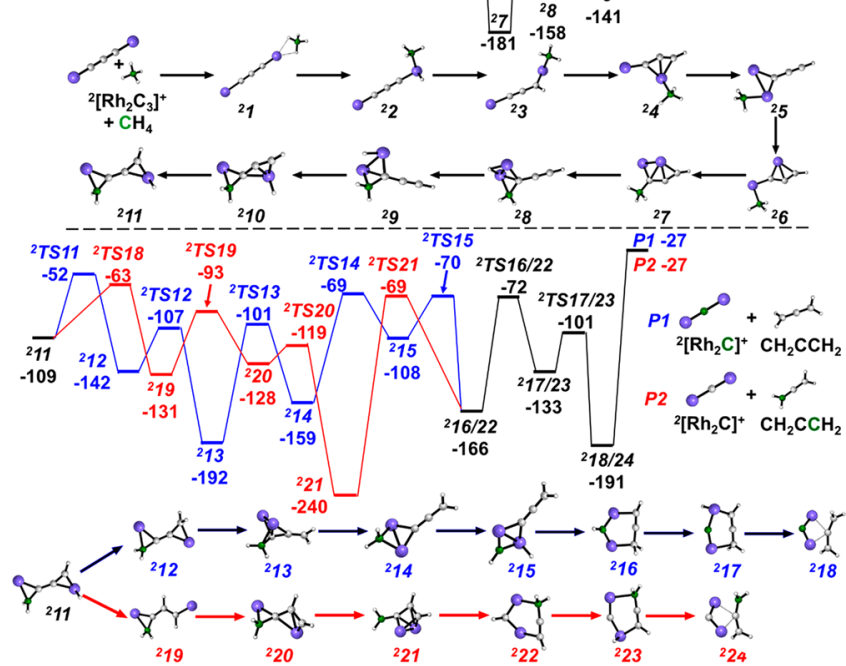

Figure 5. Simulated potential energy profiles for the reaction of $\left[\mathrm{Rh}_{2} \mathrm{C}_{3}\right]^{+}$with $\mathrm{CH}_{4}$ generating the $\left[\mathrm{Rh}_{2} \mathrm{C}\right]^{+}+\mathrm{C}_{3} \mathrm{H}_{4}$ (allene) products at the B3LYP-D3 level. The relative energies of the reaction intermediates, transition states, and products with respect to the ground-state reactants are given in $\mathrm{kJ} / \mathrm{mol}$. Purple, Rh; gray, C; green, ${ }^{13} \mathrm{C}$; white, $\mathrm{H}$.

hydrogen atoms with a $\mathrm{Rh}-\mathrm{H}$ distance of $2.06 \AA$. The first $\mathrm{C}-$ $\mathrm{H}$ bond cleavage of $\mathrm{CH}_{4}$ on the $\mathrm{Rh}$ center results in the formation of intermediate ${ }^{2} 2(-64 \mathrm{~kJ} / \mathrm{mol})$ via transition state ${ }^{2}$ TS1 $(-9 \mathrm{~kJ} / \mathrm{mol})$. The $\mathrm{H}$ atom is then transferred from the $\mathrm{Rh}$ center to the nearby carbon atom to form ${ }^{2} 3(-71 \mathrm{~kJ} / \mathrm{mol})$ via ${ }^{2} \mathrm{TS} 2$. This $\mathrm{H}$ atom transfer process is the rate-determining step for the overall reactions with the transition state $\left({ }^{2} \mathrm{TS} 2\right)$ lying at about the same energy level as the initial reactants $(+0$ $\mathrm{kJ} / \mathrm{mol}$ ). The relatively high barrier of ${ }^{2} \mathrm{TS} 2$ may be the reason why the overall reactions have low efficiency.

For the generation of the $\left[\mathrm{Rh}_{2} \mathrm{C}\right]^{+}$ions with the carbon atom originating from $\mathrm{CH}_{4}$ (P1 with the carbon atom in green in Figure 5), all four $\mathrm{H}$ atoms of $\mathrm{CH}_{4}$ are transferred step by step to the $\mathrm{C}_{3}$ moiety of $\left[\mathrm{Rh}_{2} \mathrm{C}_{3}\right]^{+}$. In each step, the hydrogen atom in the $\mathrm{CH}_{n}$ moiety $(n=1-4)$ is transferred via ${ }^{2} \mathrm{TS} 1(-9$ $\mathrm{kJ} / \mathrm{mol}),{ }^{2} \mathrm{TS} 7(-89 \mathrm{~kJ} / \mathrm{mol}),{ }^{2} \mathrm{TS} 14(-69 \mathrm{~kJ} / \mathrm{mol})$, and ${ }^{2}$ TS16 $(-72 \mathrm{~kJ} / \mathrm{mol})$ forming the rhodium hydride intermediates. For the generating of the $\left[\mathrm{Rh}_{2} \mathrm{C}\right]^{+}$ions with the carbon atom originating from $\left[\mathrm{Rh}_{2} \mathrm{C}_{3}\right]^{+}(\mathbf{P 2}$ in Figure 5), only two $\mathrm{C}-\mathrm{H}$ bonds of $\mathrm{CH}_{4}$ need to be activated. The most favorable pathway to form P2 (in red) is different from that of the P1 channel (in blue) starting from the common intermediate ${ }^{2} 11$. We can find that the ${ }^{13} \mathrm{C}$ from methane can exchange with the carbons from the $\mathrm{C}_{3}$ unit except for the central carbon in the $\mathbf{P 2}$ channel or exchange with the whole $\mathrm{C}_{3}$ unit in the $\mathbf{P 1}$ channel. This might be responsible for the experimental observation that the peak of $\left[\mathrm{Rh}_{2} \mathrm{C}\right]^{+}$is about twice as large as that of $\left[\mathrm{Rh}_{2}{ }^{13} \mathrm{C}\right]^{+}$in the mass spectrum shown in Figure 4c. The pathways for generating $\left[\mathrm{Rh}_{2} \mathrm{C}\right]^{+}+$ $\mathrm{CH}_{3} \mathrm{CCH}$ (propyne) are also calculated (Figures S4 and S5), which are very similar to those for generating $\left[\mathrm{Rh}_{2} \mathrm{C}\right]^{+}+$ $\mathrm{CH}_{2} \mathrm{CCH}_{2}$ (allene).
The two most favorable pathways for generating the $\left[\mathrm{Rh}_{2} \mathrm{C}_{2} \mathrm{H}_{2}\right]^{+}+\mathrm{C}_{2} \mathrm{H}_{2}$ (acetylene) products (reaction 2) are shown in Figure S7. The most stable structure of $\left[\mathrm{Rh}_{2} \mathrm{C}_{2} \mathrm{H}_{2}\right]^{+}$ has a doublet ground state with $C_{2 v}$ symmetry, in which the $\mathrm{C}_{2} \mathrm{H}_{2}$ moiety is side-on bonded to the $\mathrm{Rh}_{2}{ }^{+}$dimer with the $\mathrm{C}_{2} \mathrm{H}_{2}$ plane perpendicular to the $\mathrm{Rh}-\mathrm{Rh}$ bond (Figure $\mathrm{S} 6$ ). As shown in Figure S7, the reaction pathways from the reactants to the ${ }^{2} 19$ and ${ }^{2} 21$ intermediates are the same as that shown in Figure 5. Starting from either the ${ }^{2} 19$ or ${ }^{2} 21$ intermediate, the reactions proceed via multiple steps including rearrangement, $\mathrm{C}-\mathrm{H}$ bond activation, and hydrogen atom transfer. The intermediate ${ }^{2} 38$ involves two equivalent $\mathrm{C}_{2} \mathrm{H}_{2}$ moieties; either one can be liberated to form the final product $\mathbf{P} 3$. This explains the experimental observation that the peaks of $\left[\mathrm{Rh}_{2} \mathrm{C}_{2} \mathrm{H}_{2}\right]^{+}$and $\left[\mathrm{Rh}_{2}{ }^{13} \mathrm{CCH}_{2}\right]^{+}$have about the same intensity as shown in Figure 4.

The most favorable pathway for generating $\left[\mathrm{Rh}_{2} \mathrm{C}_{4} \mathrm{H}_{2}\right]^{+}+$ $\mathrm{H}_{2}$ (reaction 3) and the optimized geometries of $\left[\mathrm{Rh}_{2} \mathrm{C}_{4} \mathrm{H}_{2}\right]^{+}$ are shown in Figures S8 and S9, respectively. The most stable structure of $\left[\mathrm{Rh}_{2} \mathrm{C}_{4} \mathrm{H}_{2}\right]^{+}$has a $\mathrm{C}_{s}$ symmetry structure, in which the $\mathrm{C}_{4} \mathrm{H}_{2}$ moiety is side-on bonded to the $\mathrm{Rh}_{2}{ }^{+}$dimer via two $\mathrm{C}$ atoms with the $\mathrm{C}_{4} \mathrm{H}_{2}$ plane perpendicular to the $\mathrm{Rh}-\mathrm{Rh}$ bond (Figure S9). The reaction pathway from the reactants to the ${ }^{2} 8$ intermediate is the same as that shown in Figure 5. From the ${ }^{2} 8$ intermediate, the reaction further proceeds via three additional intermediates and three transition states in forming the final products $\left[\mathrm{Rh}_{2} \mathrm{C}_{4} \mathrm{H}_{2}\right]^{+}+\mathrm{H}_{2}$ with the highest transition state $\left({ }^{2}\right.$ TS44) lying $8 \mathrm{~kJ} / \mathrm{mol}$ below the initial reactants.

The above-mentioned calculation results indicate that all of the three reaction channels are exothermic and all of the intermediates and transition states are about the same or lower in energy than the ground state reactants. Therefore, reactions $1-3$ are all thermodynamically exothermic but with low reaction efficiency. The rate-limiting transition state is ${ }^{2}$ TS2 for all three reactions. The transition state past ${ }^{2} \mathrm{TS} 2$ that limits the loss of $\mathrm{C}_{3} \mathrm{H}_{4}$ is the same as that limits the loss of $\mathrm{C}_{2} \mathrm{H}_{2}$ $\left({ }^{2} \mathrm{TS} 6,-17 \mathrm{~kJ} / \mathrm{mol}\right)$. In contrast, the transition state past ${ }^{2} \mathrm{TS} 2$ that limits the loss of $\mathrm{H}_{2}$ is ${ }^{2} \mathrm{TS} 44$, which lies only $8 \mathrm{~kJ} / \mathrm{mol}$ lower in energy than the reactants. These results are consistent with the experimental observation that the $\left[\mathrm{Rh}_{2} \mathrm{C}\right]^{+}$and $\left[\mathrm{Rh}_{2} \mathrm{C}_{2} \mathrm{H}_{2}\right]^{+}$product ions have comparable intensities, in contrast, the $\left[\mathrm{Rh}_{2} \mathrm{C}_{4} \mathrm{H}_{2}\right]^{+}$product ion is much weak than $\left[\mathrm{Rh}_{2} \mathrm{C}\right]^{+}$and $\left[\mathrm{Rh}_{2} \mathrm{C}_{2} \mathrm{H}_{2}\right]^{+}$in the mass spectrum (Figure 4).

The reactions of transition metal carbide ions with methane have previously been studied using mass spectrometric methods in the gas phase under room-temperature or even high-temperature conditions. ${ }^{30-41}$ The generation of ethylene or acetylene via $\mathrm{C}-\mathrm{H}$ bond activation and $\mathrm{C}-\mathrm{C}$ coupling reactions has been reported for some metal carbide cation reactions. ${ }^{30-32,35} \mathrm{C}-\mathrm{H}$ bond activation and dehydrogenation of methane has also been observed for metal carbide anions. ${ }^{38-40}$ The $\left[\mathrm{Rh}_{2} \mathrm{C}_{3}\right]^{+}$cation exhibits reactivity toward methane. Besides the production of acetylene, the generation of allene or propyne is also observed as a major reaction channel. The isotopic-labeled experiments reveal two different formation mechanisms of the allene or propyne product, demonstrating that the linear $\mathrm{C}_{3}$ moiety of $\left[\mathrm{Rh}_{2} \mathrm{C}_{3}\right]^{+}$can be effectively replaced by the bare carbon atom of methane with all four $\mathrm{C}-\mathrm{H}$ bonds being activated.

The calculations indicate that the rhodium centers in $\left[\mathrm{Rh}_{2} \mathrm{C}_{3}\right]^{+}$are the reactive sites for methane activation. Natural population analysis shows that both rhodium centers are 
positively charged in the linear $\left[\mathrm{Rh}_{2} \mathrm{C}_{3}\right]^{+}$cation $(+0.80$ e and $+0.82 \mathrm{e}$ in the doublet and quartet states for the rhodium center with longer $\mathrm{Rh}-\mathrm{C}$ bond length; +0.46 e and +0.48 e for the rhodium center with shorter $\mathrm{Rh}-\mathrm{C}$ bond length, see Figure S10), which can interact with methane via ion-induced dipole interactions in forming weakly bound complex. The coordination elongates the $\mathrm{C}-\mathrm{H}$ bonds of methane from 1.09 to $1.10 \AA$, which facilitates the $\mathrm{C}-\mathrm{H}$ bond activation. Calculations indicate that the first $\mathrm{C}-\mathrm{H}$ bond activation takes place on one rhodium center in forming the oxidative $\mathrm{C}-$ $\mathrm{H}$ bond insertion intermediate ${ }^{2} 2$, from which the hydride $\mathrm{H}$ atom can further be transferred to the nearby carbon atom. The process from ${ }^{2} \mathbf{2}$ to ${ }^{2} 3$ is predicted to be the ratedetermining step that requires overcoming the highest barrier. Thus, ${ }^{2} \mathbf{2}$ serves as a key intermediate along the reaction paths. It has been shown that the ground-state neutral rhodium atom is reactive toward methane and undergoes oxidative $\mathrm{C}-\mathrm{H}$ bond insertion to form the $\mathrm{HRhCH}_{3}$ species even at cryogenic temperatures. ${ }^{69}$ However, previous studies indicate that the $\mathrm{Rh}^{+}$cation is unreactive toward methane at thermal energies. ${ }^{70}$ These studies imply that the charge of the metal center is not an important factor on the reactivity as the rate-determining step was predicted to be hydrogen/hydride transfer process. Previous investigations indicate that some dinuclear metal complexes and clusters exhibit much higher reactivity than mononuclear species toward small molecule activation such as methane and dinitrogen. ${ }^{71-76}$ The cooperation of two metal centers could facilitate the activation processes. The investigation on methane activation by rhodium clusters implies that although the atomic $\mathrm{Rh}^{+}$is not able to dehydrogenate methane at room temperature, the dimer cation $\mathrm{Rh}_{2}{ }^{+}$reacts with methane to form the dehydrogenated product $\mathrm{Rh}_{2} \mathrm{CH}_{2}+24,70$

\section{CONCLUSIONS}

The dinuclear metal carbide ions $\left[\mathrm{Rh}_{2} \mathrm{C}_{3}\right]^{+}$are generated in the gas phase. It is characterized by infrared photodissociation spectroscopy as well as quantum chemical calculations to have an unsymmetrical linear $[\mathrm{Rh}-\mathrm{C}-\mathrm{C}-\mathrm{C}-\mathrm{Rh}]^{+}$structure existing in two nearly isoenergetic doublet and quartet spin states. Mass spectrometric studies on the reactions of the $\left[\mathrm{Rh}_{2} \mathrm{C}_{3}\right]^{+}$ion with $\mathrm{CH}_{4}$ in the gas phase at room temperature show that three reaction channels are observed with a quite low reaction efficiency. The first channel is the formation of the $\left[\mathrm{Rh}_{2} \mathrm{C}\right]^{+}$ cation with the release of an allene or propyne neutral $\mathrm{C}_{3} \mathrm{H}_{4}$. The second channel is the generation of the $\left[\mathrm{Rh}_{2} \mathrm{C}_{2} \mathrm{H}_{2}\right]^{+}$ion with the concomitant elimination of an acetylene molecule. The third channel is the generation of the $\left[\mathrm{Rh}_{2} \mathrm{C}_{4} \mathrm{H}_{2}\right]^{+}$ion with the release of a dihydrogen molecule. The production of $\left[\mathrm{Rh}_{2}{ }^{13} \mathrm{C}\right]^{+}+\mathrm{C}_{3} \mathrm{H}_{4}$ using isotopic-labeled ${ }^{13} \mathrm{CH}_{4}$ sample indicates that the linear $\mathrm{C}_{3}$ moiety of the $\left[\mathrm{Rh}_{2} \mathrm{C}_{3}\right]^{+}$reactant can be replaced by the bare carbon atom of methane with all the four $\mathrm{C}-\mathrm{H}$ bonds being activated. The calculations suggest that the overall reactions are thermodynamically exothermic, and that the two $\mathrm{Rh}$ centers are the reactive sites for $\mathrm{C}-\mathrm{H}$ bond activation and hydrogen atom transfer reactions. The results may provide useful information in understanding multifaceted mechanisms of methane activation at ambient conditions.

\section{ASSOCIATED CONTENT}

\section{Supporting Information}

The Supporting Information is available free of charge at https://pubs.acs.org/doi/10.1021/jacsau.1c00265.

Experimental mass spectra, calculated geometries and potential energy profiles (PDF)

\section{AUTHOR INFORMATION}

Corresponding Authors

Xiao-Nan Wu - Department of Chemistry, Collaborative Innovation Center of Chemistry for Energy Materials, Shanghai Key Laboratory of Molecular Catalysis and Innovative Materials, Fudan University, Shanghai 200438, China; (1) orcid.org/0000-0003-3076-8064;

Email: wuxiaonan@fudan.edu.cn

Mingfei Zhou - Department of Chemistry, Collaborative Innovation Center of Chemistry for Energy Materials, Shanghai Key Laboratory of Molecular Catalysis and Innovative Materials, Fudan University, Shanghai 200438, China; (ㅇ) orcid.org/0000-0002-1915-6203;

Email: mfzhou@fudan.edu.cn

\section{Authors}

Hechen Wu - Department of Chemistry, Collaborative Innovation Center of Chemistry for Energy Materials, Shanghai Key Laboratory of Molecular Catalysis and Innovative Materials, Fudan University, Shanghai 200438, China; o orcid.org/0000-0003-0424-6385

Xiaoyang Jin - Department of Chemistry, Collaborative Innovation Center of Chemistry for Energy Materials, Shanghai Key Laboratory of Molecular Catalysis and Innovative Materials, Fudan University, Shanghai 200438, China

Yangyu Zhou - Department of Chemistry, Collaborative Innovation Center of Chemistry for Energy Materials, Shanghai Key Laboratory of Molecular Catalysis and Innovative Materials, Fudan University, Shanghai 200438, China

Wei Li - Department of Chemistry, Collaborative Innovation Center of Chemistry for Energy Materials, Shanghai Key Laboratory of Molecular Catalysis and Innovative Materials, Fudan University, Shanghai 200438, China

Chonglei Ji - Department of Chemistry, Collaborative Innovation Center of Chemistry for Energy Materials, Shanghai Key Laboratory of Molecular Catalysis and Innovative Materials, Fudan University, Shanghai 200438, China; orcid.org/0000-0001-7930-2324

Complete contact information is available at: https://pubs.acs.org/10.1021/jacsau.1c00265

Notes

The authors declare no competing financial interest.

\section{ACKNOWLEDGMENTS}

The authors appreciate an anonymous reviewer for the constructive suggestions, in particular, the explanation for the $2: 1$ ratio of $\left[\mathrm{Rh}_{2} \mathrm{C}\right]^{+}$and $\left[\mathrm{Rh}_{2}{ }^{13} \mathrm{C}\right]^{+}$observed in the experiments. The authors gratefully acknowledge financial support from the National Natural Science Foundation of China (Grants 21603037, 21688102, 21973016, 21927805, and 21803013). 


\section{REFERENCES}

(1) Ruscic, B. Active Thermochemical Tables: Sequential Bond Dissociation Enthalpies of Methane, Ethane, and Methanol and the Related Thermochemistry. J. Phys. Chem. A 2015, 119, 7810-7837.

(2) Crabtree, R. H. Aspects of Methane Chemistry. Chem. Rev. 1995, 95, 987-1007.

(3) Dyker, G. Transition Metal Catalyzed Coupling Reactions Under C-H Activation. Angew. Chem., Int. Ed. 1999, 38, 1698-1712.

(4) Schwach, P.; Pan, X. L.; Bao, X. H. Direct Conversion of Methane to Value-Added Chemicals over Heterogeneous Catalysts: Challenges and Prospects. Chem. Rev. 2017, 117, 8497-8520.

(5) Gunsalus, N. J.; Koppaka, A.; Park, S. H.; Bischof, S. M.; Hashiguchi, B. G.; Periana, R. A. Homogeneous Functionalization of Methane. Chem. Rev. 2017, 117, 8521-8573.

(6) Zhang, Q.; Yu, J. H.; Corma, A. Applications of Zeolites to C1 Chemistry: Recent Advances, Challenges, and Opportunities. Adv. Mater. 2020, 32, 2002927.

(7) Hickman, D. A.; Schmidt, L. D. Production of Syngas by Direct Catalytic Oxidation of Methane. Science 1993, 259, 343-346.

(8) Guo, X. G.; Fang, G. Z.; Li, G.; Ma, H.; Fan, H. J.; Yu, L.; Ma, C.; Wu, X.; Deng, D. H.; Wei, M. M.; Tan, D. L.; Si, R.; Zhang, S.; Li, J. Q.; Sun, L. T.; Tang, Z. C.; Pan, X. L.; Bao, X. H. Direct, Nonoxidative Conversion of Methane to Ethylene, Aromatics, and Hydrogen. Science 2014, 344, 616-619.

(9) Tomkins, P.; Ranocchiari, M.; van Bokhoven, J. A. Direct Conversion of Methane to Methanol Under Mild Conditions Over $\mathrm{Cu}$ Zeolites and Beyond. Acc. Chem. Res. 2017, 50, 418-425.

(10) Agarwal, N.; Freakley, S. J.; McVicker, R. U.; Althahban, S. M.; Dimitratos, N.; He, Q.; Morgan, D. J.; Jenkins, R. L.; Willock, D. J.; Taylor, S. H.; Kiely, C. J.; Hutchings, J. G. Aqueous Au-Pd Colloids Catalyze Selective $\mathrm{CH}_{4}$ Oxidation to $\mathrm{CH}_{3} \mathrm{OH}$ with $\mathrm{O}_{2}$ Under Mild Conditions. Science 2017, 358, 223-226.

(11) Liang, Z.; Li, T.; Kim, M.; Asthagiri, A.; Weaver, J. F. LowTemperature Activation of Methane on the $\mathrm{IrO}_{2}(110)$ Surface. Science 2017, 356, 299-303.

(12) Diaz-Urrutia, C.; Ott, T. Activation of Methane to $\mathrm{CH}_{3}{ }^{+}: \mathrm{A}$ Selective Industrial Route to Methanesulfonic Acid. Science 2019, 363, $1326-1329$.

(13) Song, Y. D.; Ozdemir, E.; Ramesh, S.; Adishev, A.; Subramanian, S.; Harale, A.; Albuali, M.; Fadhel, B. A.; Jamal, A.; Moon, D.; Choi, S. H.; Yavuz, C. T. Dry Reforming of Methane by Stable Ni-Mo Nanocatalysts on Single-Crystalline MgO. Science 2020, 367, 777-781.

(14) Wang, G. J.; Zhou, M. F. Probing the Intermediates in the MO $+\mathrm{CH}_{4} \leftrightarrow \mathrm{M}+\mathrm{CH}_{3} \mathrm{OH}$ Reactions by Matrix Isolation Infrared Spectroscopy. Int. Rev. Phys. Chem. 2008, 27, 1-25.

(15) Roithová, J.; Schröder, D. Selective Activation of Alkanes by Gas Phase Metal Ions. Chem. Rev. 2010, 110, 1170-1211.

(16) Schwarz, H. Chemistry with Methane: Concepts Rather than Recipes. Angew. Chem., Int. Ed. 2011, 50, 10096-10115.

(17) Schwarz, H. Thermal Hydrogen-Atom Transfer from Methane: A Mechanistic Exercise. Chem. Phys. Lett. 2015, 629, 91-101.

(18) Zhao, Y. X.; Li, Z. Y.; Yang, Y.; He, S. G. Methane Activation by Gas Phase Atomic Clusters. Acc. Chem. Res. 2018, 51, 2603-2610.

(19) Irikura, K. K.; Beauchamp, J. L. Electronic Structure Considerations for Methane Activation by Third-Row TransitionMetal Ions. J. Phys. Chem. 1991, 95, 8344-8351.

(20) Ranasinghe, Y. A.; MacMahon, T. J.; Freiser, B. S. Formation of Thermodynamically Stable Dications In the Gas Phase by Thermal Ion-Molecule Reactions: $\mathrm{Ta}^{2+}$ and $\mathrm{Zr}^{2+}$ with Small Alkanes. J. Phys. Chem. 1991, 95, 7721-7726.

(21) Owen, C. J.; Boles, G. C.; Chernyy, V.; Bakker, J. M.; Armentrout, P. B. Structures of the Dehydrogenation Products of Methane Activation by 5d Transition Metal Cations Revisited: Deuterium Labeling and Rotational Contours. J. Chem. Phys. 2018, $148,044307$.

(22) Achatz, U.; Berg, C.; Joos, S.; Fox, B. S.; Beyer, M. K.; NiednerSchatteburg, G.; Bondybey, V. E. Methane Activation by Platinum
Cluster Ions in the Gas Phase: Effects of Cluster Charge on the Pt Tetramer. Chem. Phys. Lett. 2000, 320, 53-58.

(23) Shayesteh, A.; Lavrov, V. V.; Koyanagi, G. K.; Bohme, D. K. Reactions of Atomic Cations with Methane: Gas Phase RoomTemperature Kinetics and Periodicities in Reactivity. J. Phys. Chem. A 2009, 113, 5602-5611.

(24) Albert, G.; Berg, C.; Beyer, M.; Achatz, U.; Joos, S.; NiednerSchatteburg, G.; Bondybey, V. E. Methane Activation by Rhodium Cluster Argon Complexes. Chem. Phys. Lett. 1997, 268, 235-241.

(25) Brungs, A. J.; York, A. P. E.; Green, M. L. H. Comparison of the Group V and VI Transition Metal Carbides for Methane Dry Reforming and Thermodynamic Prediction of Their Relative Stabilities. Catal. Lett. 1999, 57, 65-69.

(26) Alexander, A. M.; Hargreaves, J. S. J. Alternative Catalytic Materials: Carbides, Nitrides, Phosphides and Amorphous Boron Alloys. Chem. Soc. Rev. 2010, 39, 4388-4401.

(27) Wan, W. M.; Tackett, B. M.; Chen, J. G. G. Reactions of Water and C1Molecules on Carbide and Metal-Modified Carbide Surfaces. Chem. Soc. Rev. 2017, 46, 1807-1823.

(28) Prats, H.; Gutierrez, R. A.; Pinero, J. J.; Vines, F.; Bromley, S. T.; Ramirez, P. J.; Rodriguez, J. A.; Illas, F. Room Temperature Methane Capture and Activation by $\mathrm{Ni}$ Clusters Supported on $\mathrm{TiC}(001)$ : Effects of Metal-Carbide Interactions on the Cleavage of the C-H Bond. J. Am. Chem. Soc. 2019, 141, 5303-5313.

(29) Figueras, M.; Gutierrez, R. A.; Prats, H.; Vines, F.; Ramirez, P. J.; Illas, F.; Rodriguez, J. A. Boosting the Activity of Transition Metal Carbides Towards Methane Activation by Nanostructuring. Phys. Chem. Chem. Phys. 2020, 22, 7110-7118.

(30) Li, J. L.; Zhou, S. D.; Schlangen, M.; Weiske, T.; Schwarz, H. Hidden Hydride Transfer as a Decisive Mechanistic Step in the Reactions of the Unligated Gold Carbide $[\mathrm{AuC}]^{+}$with Methane under Ambient Conditions. Angew. Chem., Int. Ed. 2016, 55, 1307213075.

(31) Schwarz, H.; Shaik, S.; Li, J. L. Electronic Effects on RoomTemperature, Gas-Phase C-H Bond Activations by Cluster Oxides and Metal Carbides: The Methane Challenge. J. Am. Chem. Soc. 2017, 139, 17201-17212.

(32) Geng, C. Y.; Li, J. L.; Weiske, T.; Schlangen, M.; Shaik, S.; Schwarz, H. Electrostatic and Charge-Induced Methane Activation by a Concerted Double C-H Bond Insertion. J. Am. Chem. Soc. 2017, $139,1684-1689$.

(33) Geng, C. Y.; Weiske, T.; Li, J. L.; Shaik, S.; Schwarz, H. Intrinsic Reactivity of Diatomic 3d Transition-Metal Carbides in the Thermal Activation of Methane: Striking Electronic Structure Effects. J. Am. Chem. Soc. 2019, 141, 599-610.

(34) Geng, C. Y.; Li, J. L.; Weiske, T.; Schwarz, H. A ReactionInduced Localization of Spin Density Enables Thermal C-H Bond Activation of Methane by Pristine $\mathrm{FeC}_{4}{ }^{+}$. Chem. - Eur. J. 2019, 25, 12940-12945.

(35) Li, Z. Y.; Yuan, Z.; Zhao, Y. X.; He, S. G. Methane Activation by Diatomic Molybdenum Carbide Cations. Chem. - Eur. J. 2014, 20, 4163-4169.

(36) Li, H. F.; Li, Z. Y.; Liu, Q. Y.; Li, X. N.; Zhao, Y. X.; He, S. G. Methane Activation by Iron-Carbide Cluster Anions $\mathrm{FeC}_{6}^{-}$. J. Phys. Chem. Lett. 2015, 6, 2287-2291.

(37) Li, H. F.; Jiang, L. X.; Zhao, Y. X.; Liu, Q. Y.; Zhang, T.; He, S. G. Formation of Acetylene in the Reaction of Methane with Iron Carbide Cluster Anions $\mathrm{FeC}_{3}{ }^{-}$under High-Temperature Conditions. Angew. Chem., Int. Ed. 2018, 57, 2662-2666.

(38) Liu, Q.-Y.; Ma, J.-B.; Li, Z.-Y.; Zhao, C.; Ning, C.-G.; Chen, H.; $\mathrm{He}$, S.-G. Activation of Methane Promoted by Adsorption of $\mathrm{CO}$ on $\mathrm{Mo}_{2} \mathrm{C}_{2}{ }^{-}$Cluster Anions. Angew. Chem., Int. Ed. 2016, 55, 5760-5764.

(39) Li, H. F.; Zhao, Y. X.; Yuan, Z.; Liu, Q. Y.; Li, Z. Y.; Li, X. N.; Ning, C. G.; He, S. G. Methane Activation by Tantalum Carbide Cluster Anions $\mathrm{Ta}_{2} \mathrm{C}_{4}^{-}$. J. Phys. Chem. Lett. 2017, 8, 605-610.

(40) Cassady, C. J.; Mcelvany, S. W. Gas Phase Reactions of Tantalum Carbide Cluster Ions with Deuterium and Small Hydrocarbons. J. Am. Chem. Soc. 1990, 112, 4788-4797. 
(41) Hirabayashi, S.; Ichihashi, M. Activation of Methane by Tungsten Carbide and Nitride Cluster Cations. J. Phys. Chem. A 2020, 124, 5274-5279.

(42) Wang, G. J.; Chi, C. X.; Xing, X. P.; Ding, C. F.; Zhou, M. F. A Collinear Tandem Time-of-Flight Mass Spectrometer for Infrared Photodissociation Spectroscopy of Mass-Selected Ions. Sci. China: Chem. 2014, 57, 172-177.

(43) Wu, X. N.; Liu, Z. Z.; Wu, H. C.; Zhang, D.; Li, W.; Huang, Z. J.; Wang, G. J.; Xu, F. X.; Ding, C. F.; Zhou, M. F. Reactions of Transition-Metal Carbyne Cations with Ethylene in the Gas Phase. J. Phys. Chem. A 2020, 124, 2628-2633.

(44) Westergren, J.; Grönbeck, H.; Kim, S. G.; Tománek, D. Noble Gas Temperature Control of Metal Clusters: A Molecular Dynamics Study. J. Chem. Phys. 1997, 107, 3071-3079.

(45) Frisch, M. J.; Trucks, G.; Schlegel, H. B.; Scuseria, G. E.; Robb, M. A.; Cheeseman, J. R.; Scalmani, G.; Barone, V.; Mennucci, B.; Petersson, G. A. et al. Gaussian 09, Revision A.01; Gaussian, Inc.: Wallingford CT, 2009.

(46) Lee, C. T.; Yang, W. T.; Parr, R. G. Development of the ColleSalvetti Correlation-Energy Formula into a Functional of the Electron-Density. Phys. Rev. B: Condens. Matter Mater. Phys. 1988, 37, 785-789.

(47) Becke, A. D. Density-Functional Thermochemistry. 3. The Role of Exact Exchange. J. Chem. Phys. 1993, 98, 5648-5652.

(48) Weigend, F.; Ahlrichs, R. Balanced Basis Sets of Split Valence, Triple Zeta Valence and Quadruple Zeta Valence Quality for H to Rn: Design and Assessment of Accuracy. Phys. Chem. Chem. Phys. 2005, 7, 3297-3305.

(49) Grimme, S.; Antony, J.; Ehrlich, S.; Krieg, H. A Consistent and Accurate ab Initio Parametrization of Density Functional Dispersion Correction (DFT-D) for the 94 Elements H-Pu. J. Chem. Phys. 2010, 132, 154104.

(50) Lu, T. Molclus Program; Beijing Kein Research Center for Natural Science: Beijing, 2016; http://www.keinsci.com/research/ molclus.html (accessed on 2021-07-04).

(51) Ruscic, B.; Bross, D. H. Active Thermochemical Tables (ATcT) values based on ver. $1.122 \mathrm{p}$ of the Thermochemical Network. Argonne National Laboratory.https://atct.anl.gov/ Thermochemical\%20Data/version\%201.122p/index.php.

(52) Robinson, M. S.; Polak, M. L.; Bierbaum, V. M.; DePuy, C. H.; Lineberger, W. C. Experimental Studies of Allene, Methylacetylene, and the Propargyl Radical: Bond Dissociation Energies, Gas-Phase Acidities, and Ion-Molecule Chemistry. J. Am. Chem. Soc. 1995, 117, 6766-6778.

(53) Chen, Y. M.; Elkind, J. L.; Armentrout, P. B. Reactions of $\mathrm{Ru}^{+}$, $\mathrm{Rh}^{+}, \mathrm{Pd}^{+}$, and $\mathrm{Ag}^{+}$with $\mathrm{H}_{2}, \mathrm{HD}$, and $\mathrm{D}_{2}$. J. Phys. Chem. 1995, 99, 10438-10445.

(54) Chen, Y. M.; Armentrout, P. B. Activation of $\mathrm{C}_{2} \mathrm{H}_{6}, \mathrm{C}_{3} \mathrm{H}_{8}$, and c- ${ }_{3} \mathrm{H}_{6}$ Gas-Phase $\mathrm{Rh}^{+}$and the Thermochemistry of Rh-Ligand Complexes. J. Am. Chem. Soc. 1995, 117, 9291-9304.

(55) Kramida, A.; Ralchenko, Y.; Reader, J. NIST Atomic Spectra Database, ver. 5.8); National Institute of Standards and Technology: Gaithersburg, MD; https://physics.nist.gov/asd (accessed 2021-0810)..

(56) Peng, C. Y.; Ayala, P. Y.; Schlegel, H. B.; Frisch, M. J. Using Redundant Internal Coordinates to Optimize Equilibrium Geometries and Transition States. J. Comput. Chem. 1996, 17, 49-56.

(57) Fukui, K. The Path of Chemical-Reactions - the IRC Approach. Acc. Chem. Res. 1981, 14, 363-368.

(58) Gonzalez, C.; Schlegel, H. B. Reaction-Path Following in MassWeighted Internal Coordinates. J. Phys. Chem. 1990, 94, 5523-5527.

(59) Computational Chemistry Comparison and Benchmark Database; National Institute of Standards and Technology, 2016; http://cccbdb. nist.gov/vibscalex.asp.

(60) Okumura, M.; Yeh, L. I.; Myers, J. D.; Lee, Y. T. Infrared Spectra of the Solvated Hydronium Ion: Vibrational Predissociation Spectroscopy of Mass-Selected $\mathrm{H}_{3} \mathrm{O}^{+}\left(\mathrm{H}_{2} \mathrm{O}\right)_{n}\left(\mathrm{H}_{2}\right)_{m}$. J. Phys. Chem. 1990, 94, 3416-3427.
(61) Bieske, E. J.; Dopfer, O. High-Resolution Spectroscopy of Cluster Ions. Chem. Rev. 2000, 100, 3963-3998.

(62) Robertson, W. H.; Johnson, M. A. Molecular Aspects of Halide Ion Hydration: The Cluster Approach. Annu. Rev. Phys. Chem. 2003, 54, 173-213.

(63) Duncan, M. A. Infrared Spectroscopy to Probe Structure and Dynamics in Metal Ion Molecule Complexes. Int. Rev. Phys. Chem. 2003, 22, 407-435.

(64) Weltner, W., Jr.; Walsh, P. N.; Angell, C. L. Spectroscopy of Carbon Vapor Condensed in Rare-Gas Matrices at 4 and $20 \mathrm{~K}$. J. Chem. Phys. 1964, 40, 1299-1305.

(65) Hinkle, K. W.; Keady, J. J.; Bernath, P. F. Detection of $\mathrm{C}_{3}$ in the Circumstellar Shell of IRC+10216. Science 1988, 241, 1319-1322.

(66) Pople, J. A.; Head-Gordon, M.; Raghavachari, K. Quadratic Configuration-interaction. A General Technique for Determining Electron Correlation Energies. J. Chem. Phys. 1987, 87, 5968-5975.

(67) Langevin, P. A Fundamental Formula of Kinetic Theory. Ann. Chim. Phys. 1905, 5, 245.

(68) Gioumousis, G.; Stevenson, D. P. Reactions of Gaseous Molecule Ions with Gaseous Molecules. V. Theory. J. Chem. Phys. 1958, 29, 294-299.

(69) Wang, G. J.; Chen, M. H.; Zhou, M. F. Activation of Methane by $\mathrm{Rh}(0)$ : Evidence for Direct Insertion of Rhodium into the $\mathrm{C}-\mathrm{H}$ Bond at Cryogenic Temperatures. Chem. Phys. Lett. 2005, 412, 4649.

(70) Chen, Y. M.; Armentrout, P. B. Activation of Methane by GasPhase $\mathrm{Rh}^{+}$. J. Phys. Chem. 1995, 99, 10775-10779.

(71) Noor, A.; Sobgwi Tamne, E.; Qayyum, S.; Bauer, T.; Kempe, R. Cycloaddition Reactions of a Chromium-Chromium Quintuple Bond. Chem. - Eur. J. 2011, 17, 6900-6903.

(72) Huang, W. L.; Dulong, F.; Khan, S. I.; Cantat, T.; Diaconescu, P. L. Bimetallic Cleavage of Aromatic C-H Bonds by Rare-EarthMetal Complexes. J. Am. Chem. Soc. 2014, 136, 17410-17413.

(73) Adams, R. D.; Rassolov, V.; Wong, Y. O. Binuclear Aromatic C$\mathrm{H}$ Bond Activation at a Dirhenium Site. Angew. Chem., Int. Ed. 2016, $55,1324-1327$.

(74) Geng, C. Y.; Li, J. L.; Weiske, T.; Schwarz, H. Ta ${ }_{2}{ }^{+}$-mediated ammonia synthesis from $\mathrm{N}_{2}$ and $\mathrm{H}_{2}$ at ambient temperature. Proc. Natl. Acad. Sci. U. S. A. 2018, 115, 11680-11687.

(75) Zhou, M. F.; Jin, X.; Gong, Y.; Li, J. Remarkable dinitrogen activation and cleavage by the Gd dimer: From dinitrogen complexes to ring and cage nitrides. Angew. Chem., Int. Ed. 2007, 46, 2911-2914.

(76) Zhao, Y.; Cui, J.-T.; Wang, M.; Valdivielso, D. Y.; Fielicke, A.; Hu, L.-R.; Cheng, X.; Liu, Q.-Y.; Li, Z.-Y.; He, S.-G.; Ma, J.-B. Dinitrogen Fixation and Reduction by $\mathrm{Ta}_{3} \mathrm{~N}_{3} \mathrm{H}_{0,1}{ }^{-}$Cluster Anions at Room Temperature: Hydrogen-Assisted Enhancement of Reactivity. J. Am. Chem. Soc. 2019, 141, 12592-12600. 